\title{
Growth Delay in Children: Experience of the Department of Metabolic and Endocrine Diseases at the Children's Hospital of Rabat
}

\author{
Touzani Asmae ${ }^{1,2}$, Tahri Joutei Abderrafie ${ }^{3}$, Khaliss Hajar ${ }^{3}$, Dami Abdellah², Balouch Lhousaine ${ }^{2}$, \\ Kriouile Yamna $^{1}$, Zineb Imane ${ }^{1}$, Gaouzi Ahmed ${ }^{1}$ \\ ${ }^{1}$ Endocrinology-Diabetology-Neurology-II-CHIS-Children's Hospital-Rabat, Faculty of Medicine and Pharmacy, University of Rabat, Rabat, \\ Morocco \\ ${ }^{2}$ Laboratory, Biochemistry and Molecular Biology, University Mohamed V, Faculty of Medicine and Pharmacy, Rabat, Morocco \\ ${ }^{3}$ Department of Biology, University Mohamed V Faculty of Sciences, Rabat, Morocco
}

Email address:

as.touzani10@gmail.com (T. Asmae)

\section{To cite this article:}

Touzani Asmae, Tahri Joutei Abderrafie, Khaliss Hajar, Dami Abdellah, Balouch Lhousaine, Kriouile Yamna, Zineb Imane, Gaouzi Ahmed. Growth Delay in Children: Experience of the Department of Metabolic and Endocrine Diseases at the Children's Hospital of Rabat. American Journal of Biomedical and Life Sciences. Vol. 9, No. 5, 2021, pp. 254-258. doi: 10.11648/j.ajbls.20210905.15

Received: September 13, 2021; Accepted: October 4, 2021; Published: October 19, 2021

\begin{abstract}
Objective: The aim of our study is to describe the epidemiological, clinical and biological aspects of staturoponderal delay and to deduce the main etiologies. Material and Methods: the study was carried out on 141 patients (78 boys and 63 girls). Patients ranged in age from 9 months to 17 years (mean: 9 years 1 month) with a statural delay that varied from 2DS to -5DS (mean: -2.5DS). Results: Analysis of the data showed a frequency of $13.5 \%$ of patients with severe growth retardation, $35 \%$ of whom had a growth hormone deficiency. The hormonal assessment showed a GH deficiency in $43 \%$ of patients with a greater difference in chronological age and bone age ( 2.5 years) than in non-deficient patients ( 2 years). Among them, $51 \%$ of patients have an elevated TSH. Magnetic resonance imaging performed in 37 cases was in favor of a pituitary anomaly in $12 \%$ of cases, including interruption of the pituitary stem ( $4 \%$ of cases), hypoplasia ( $3 \%$ of cases), an adenoma ( $1 \%$ of cases) and an empty sella turcica in $4 \%$ of cases. Conclusion: Severe central growth retardation is common. Systematic monitoring and follow-up of growth is essential in children, as is vaccination, in order to identify and manage early any causal pathology that may disrupt the child's growth.
\end{abstract}

Keywords: Growth, Delay, Ethiologies, Stature-Weight, Children

\section{Introduction}

Growth is a complex biological phenomenon through which living beings, as they increase their mass, mature morphologically and progressively acquire their full functional capacity. Stunting in children results from undenutrition and is correlated with disturbances in neurocognitive development. The World Health Assembly's goal is to reduce the number of stunted children under five years of age by $40 \%$ by 2025 [1].

Growth retardation is a very frequent reason for consultation in pediatrics. It is defined by a height below or equal to - 2 standard deviations (SD) of the average height for an age and a sex. In Morocco the standard is that of the French population as determined by Sempé and Pedron [2].

It can be the first sign of a pathological process directly endangering the vital or functional prognosis of the child.

Children with A short stature have a height less than 2 standard deviations below the mean [3]. Stature delay is said to be "severe" when height is less than or equal to -3 SD [4]. Statural growth retardation can be of pathological origin [5]. It can be secondary to a chronic disease, a nutritional defect, a bone disease or a hormonal or endocrine anomaly. Intrauterine growth 
retardation (IUGR) and growth problems in children result in $26 \%$ of children under 5 years of age worldwide being stunted, and $8 \%$ being too thin for their height (WHO). The burden of stunting has halved in Asia and Latin America/Caribbean, but has increased by $24 \%$ in Africa during the same period [5].

In Morocco, stunting in children has an incidence of $16.5 \%$ compared to a world average of $27 \%$, and $29 \%$ in developing countries according to the WHO. Monitoring of growth and development is essential. It must be part of the systematic follow-up of every child, of the same importance as vaccination, in order to detect and take early care of any causal pathology that could disturb the good progress of the child's life. However, not recognizing a growth delay means not identifying a situation that is accessible to a treatment that would allow improving or even normalizing the height.

Our work aims to identify patients with stunted growth who are followed in the pediatric department at the Chu of Rabat. This on the one hand and on the other hand to deduce the different etiologies identified.

\section{Materials and Methods}

\subsection{Study Type}

This is a retrospective study of 140 cases of patients with short stature out of 720 records of children followed in pediatric endocrinology consultation at the children's hospital of Rabat for a period between 2011-2014. The study took place between March 19, 2015 until April 30, 2015.

\subsubsection{Patients}

The children included were boys and girls followed up in a pediatric consultation for short stature and with staturo-ponderal growth delay. Files with insufficient clinical, paraclinical or biological data were excluded from the study.

\subsubsection{Clinical Parameters for Growth Assessment}

1. Height: is measured in the supine position (length) until the age of 2-3 years and then standing (height). Expressed in absolute value and in standard deviation (SD) following the growth curve.

2. Weight: measured with the child undressed. Expressed in $\mathrm{cm}$ and standard deviation (SD).

\subsection{Calculated Parameters}

1. The growth rate $(\mathrm{cm} /$ year): it represents the number of $\mathrm{cm}$ acquired in one year.

2. Body mass index BMI $\left(\mathrm{kg} / \mathrm{cm}^{2}\right)$ : this is the ratio of weight to height squared. It reflects the nutritional status and the fat mass.

3. target height: this describes the genetic potential for height that an individual is programmed to achieve due to the high heredity of height:

TC $(\mathrm{cm})=\frac{\text { Father's height }(\mathrm{cm})+\text { Mother } / \mathrm{s} \text { height }(\mathrm{cm}) \pm 13 \mathrm{~cm} \text { by sex }}{2}$

Establishment of a Growth Curve

It is an essential step in the approach of a growth delay in a child. This growth curve (height, weight and possibly BMI curves) allows:

1. To appreciate the importance of the growth delay by calculating the height delay in SD/age.

2. To establish the growth rate and thus to differentiate between growth retardation with normal growth rate (old retardation and not getting worse), and growth retardation with slow growth rate (recent retardation and getting worse).

3. To determine the statural age which is the age that corresponds to the height of the child.

4. To compare the evolution of weight and the evolution of height.

\subsection{Biological Markers for Growth Assessment}

TSH Us (Thyroid Stimulating Hormone)

$\mathrm{TSH}$ is the most sensitive indicator to assess thyroid dysfunction very often in the case of growth retardation hypothyroidism when the TSH level exceeds $7 \mu \mathrm{UI} / \mathrm{ml}$.

Lt4 (Free Thyroxin)

A decrease in blood T4 level (below $0.7 \mathrm{ng} / \mathrm{dl}$ ) is indicative of hypothyroidism.

IGF-1

A decreased plasma level in relation to the child's age may indicate a growth hormone deficiency.

\section{Results}

Out of 720 patients who are seen in consultation in the endocrinology-pediatrics department. 140 patients are followed up for a delay in weight and height, which is a prevalence of $19.5 \%$. This makes it the first reason for consultation in pediatric endocrinology. In our study, $55 \%$ of the children who consulted for staturo-ponderal retardation were male $(\mathrm{n}=78)$, while girls represented.

$45 \%(n=63)$. The sex ratio is thus 1.2 . The average age was 9 years and 01 months with a minimum of 09 months and a maximum of 17 years, with a peak in frequency between the ages of 4 and 12 years.

Weight: The mean weight of the patients studied at the first visit was $-2 \mathrm{DS}$ with extremes ranging from $-4 \mathrm{SD}$ to $-1 \mathrm{SD}$. A weight $\leq-4 \mathrm{DS}$ was present in 3 patients or $2.12 \%$.

Height: They ranged from -5 SD to -1 DS for age with a mean of -2.5 SD. $13.5 \%$ of the children was in the dwarfism stage $(\leq-4 \mathrm{SD})$. 


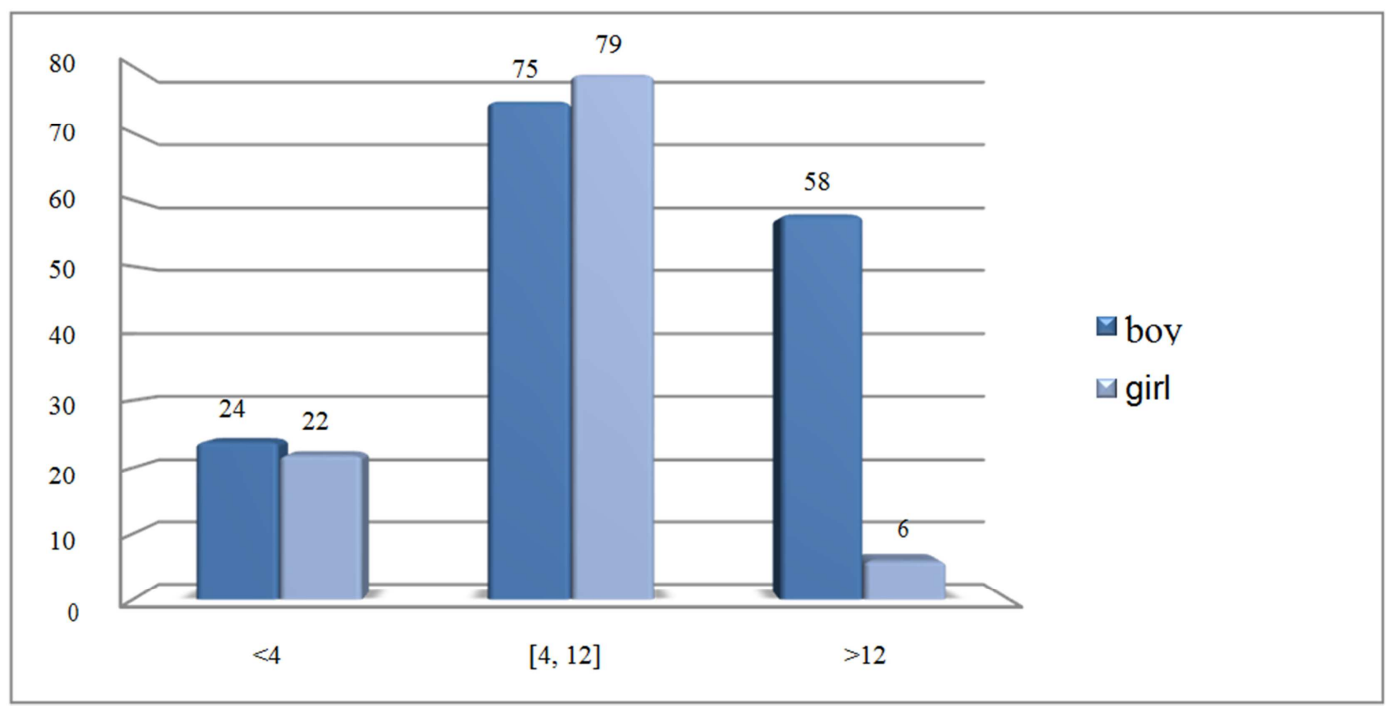

Figure 1. Distribution of patients by age.

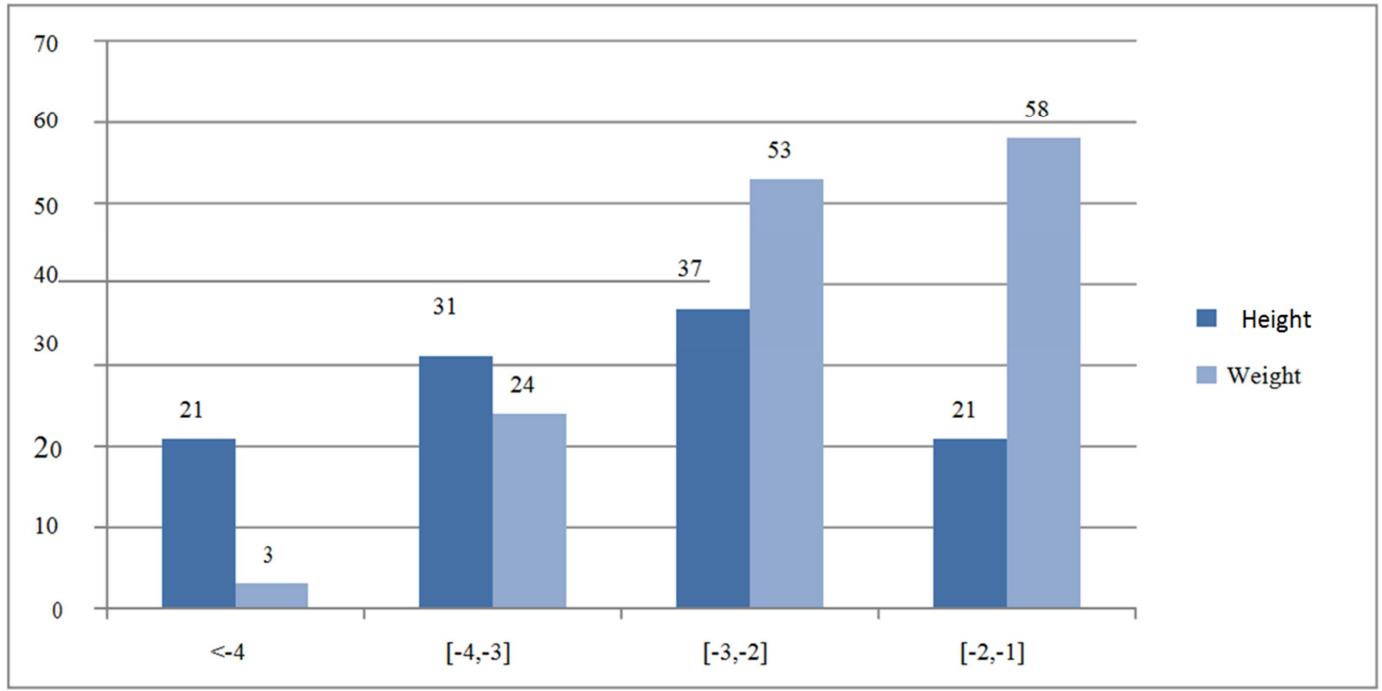

Figure 2. Distribution of patients by height and weight in standard deviations.

Bone Age X-rays of the left hand and wrist were taken in 103 patients and interpreted according to the reading method of GREULICH and PYLE.

The average bone age was 6 years 03 months with extremes between 3 months and 17 years.

The chronological age (CA) - Bone age difference varies from 01 month to 7 years and 06 months, with an average of 2 years and 4 months. 29 cases have a difference CA-BA $\leq 1$ years, 17 cases have a difference between [1 year, 2years], 40 cases have a difference CA-BA between [2 years, 4 years ] and 18 cases have a difference $\mathrm{CA}-\mathrm{BA}>4$ years.

\section{Growth hormone stimulation test:}

The test was performed in 79 cases and came back positive in 61 of them, which represents $77 \%$.

The stimulation test was performed in 79 patients. GH deficiency was found in 61 patients, which represents $77 \%$. GH deficiency $(<20 \mathrm{ng} / \mathrm{mL})$ was observed after injection of the stimulating agent. No GH deficiency was found in the group with a stimulation $\mathrm{GH}>20 \mathrm{ng} / \mathrm{mL}$.

Among 140 patients studied, 64\% (90/140) had IGF-1 assays. We found that $69 \%(62 / 90)$ had normal IGF-1 levels for their ages, while $12 \%$ (11/90) had a low limit for age and $19 \%$ had a collapsed IGF-1 level for age.

Pituitary MRI was performed in only 37 patients. We retained $12 \%$ of the patients who present pituitary anomalies: $4 \%$ have an interruption of the pituitary stem, 3\% have a hypoplasia, $1 \%$ has a pituitary adenoma and $4 \%$ have an empty sella turcica. The pituitary MRI was not done in $74 \%$ of the patients.

Among 140 subjects, 100 were tested for thyroid stimulating hormone (TSHus). The results showed that $51 \%$ $(52 / 100)$ of the patients had an elevated TSHus $(>2 \mathrm{UI} / \mathrm{L}$ which $55 \%$ were boys and $45 \%$ were girls). Among 74 cases who had LT4 measurement, $5 \%$ had a decreased level $(<0.7$ ng/dl). 


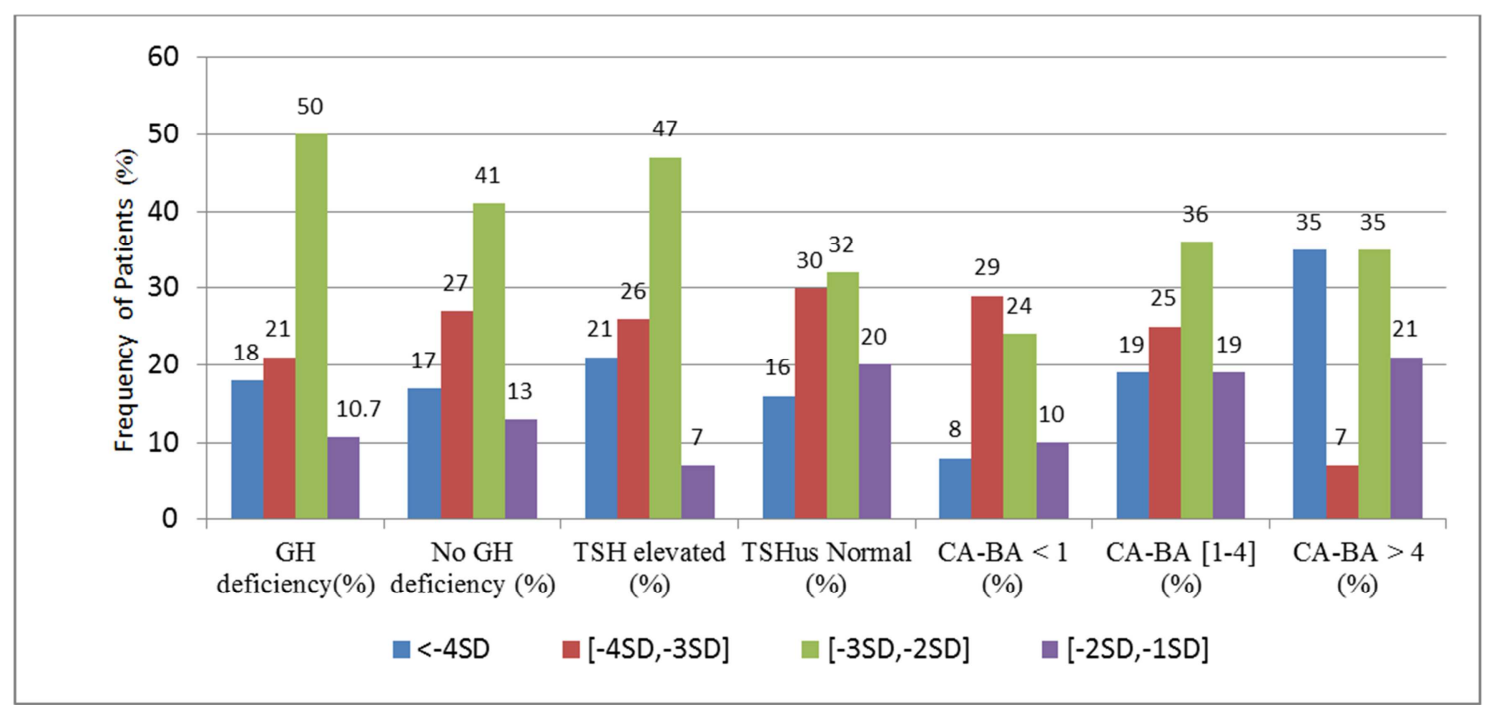

Figure 3. Relationship between the result of the stimulation test, the TSHus level, the difference between chronological age-bone age and stature delay in patients.

The result of the GH stimulation test and the severity of stunting show a high peak frequency in the group of patients with -3 SD and -2SD height with GH deficiency $(50 \%)$ and without deficiency $(41 \%)$. In this same group, the frequency is high (45\%) in patients with an elevated TSHus and $32 \%$ have a normal TSH.

Our study shows the relationship between the difference between chronological age and bone age and the severity of the statural delay. For this purpose, we calculated the percentage of patients according to the CA-BA difference in each height group. Our results show a high percentage $35 \%$ of patients with a difference of more than 4 years in the group with severe stunting (<-4SD and in the group with stunting between [-3SD,-2SD ]).

\section{Discussion}

Among subjects, $19.5 \%$ had pathologic short stature and $80.5 \%$ had normal variants growth. This prevalence is low compared to that found by other authors which are 37\% [6]. In our study population, we noted a predominance of males in children with growth retardation (55\% of subjects) with a sex ratio of 1.2. This is in agreement with what has been reported by other authors [7-9]. Our results show that the average age at the first consultation is 9 years, which is identical to that found by other reporters [7, 8]. Another study show the average age at first consultation is 15 years [10]; this shows an initial management of stunting in our study that allowed a start of growth hormone treatment in our patients, with a satisfactory statural gain depending on the cause. In current practice, plasma IGF-1 remains a marker sensitive to the effect of growth hormone, we found a low IGF-1 level in $31 \%$ of patients. In Algeria, reporters have found a low level in $95 \%$ and $100 \%$ of patients respectively [11]. Growth retardation is also thought to be due to malnutrition or an unbalanced diet. Several international institutions have reported the importance of nutrition in child growth, including the World Bank [12, 13], the World Health Organization [14], the Food and Agriculture Organization of the United Nations [15] and UNICEF [16].

The thyroid workup shows discordant results; in our work we observed an increase in TSH in $51 \%$ and a decrease in T4 in only $4 \%$ of patients. While in another study, the increase of TSHus is found in only $13 \%$ and the decrease of T4 in $15 \%$ of the cases. On the other hand, other studies agree on the severity of statural retardation in GH deficiency, this diagnosis is evoked when the growth rate is slowed down and it becomes insufficient to maintain the child's height in the normal range with stable SD over time. This progressive or abrupt loss of height often results in a height less than 2SD below the average for the age. In our series, we found a mean height of $-2.6 \mathrm{SD}$ which corresponds to a GH deficiency. This value is comparable to that found in other studies 2.6DS [10] and -3DS in Greece [17]. In addition, other authors have reported a severe delay in patients with growth retardation: either the study done in Iran in 2004 (-6.7DS) [5 or by others (-4.9 DS) [5].

Bone age is also affected in GH deficiency, we found a difference chronological age-bone age of 1.7 years, this difference is close to the study of Papadimitriou et al and which is 1.5 years and the study of Hamidoun MH which is 1.8 years. On the other hand, the difference $\mathrm{BA}-\mathrm{AO}$ is more important in the studies made by other authors ( 4.5 years and 5.7 years) $[5,19]$ respectively. The impact of the covid 19 pandemic on children's mental health, development and growth is documented [20]. This has caused stress, psychological disorders and sometimes depression in children.

\section{Conclusion}

Stunting is a public health problem, as growth is a reflection of a child's health and life course. The reasons for stunting are many and varied. The orientation of the 
diagnosis towards one of the great known etiological frameworks requires the analysis of the data of the biological and clinical examination, as well as the bone maturation to determine the definitive statural prognosis, and especially not to leave a cause susceptible to be raised by a specific treatment. The important delay of the consultation age as well as the heaviness of the paraclinical assessment and the stimulation tests constitute the main difficulties encountered in the management of growth retardation. But, the major obstacle is the cost of hormonal treatment which is still at the stage of challenge in our country.

\section{References}

[1] Unicef-Who-World Bank Joint child malnutrition estimates. New York: Unicef; Geneva: World Health Organization; Washington DC: The World Bank; 2012, updated 2013. (http://apps.who.int/gho/data/node.main.ngest?

[2] Sempe M, Heanggeli CA, Sizonenko PC. (1996). Croissance et développement de l'enfant et de l'adolescent in : Sizonenki PC, Criscelli C précis de pédiatrie. Edition Payot Lausanne Paris : 67-69.

[3] Alan D Rogol, Gregory F Hayden. (2014). Etiologies and early diagnosis of short stature and growth failure in children and adolescents. J. Pediatr. 164 (5 Suppl): S1-14.

[4] Craig Barstow, Caitlyn Rerucha. (2015). Evaluation of Short and Tall Stature in Children. Am Fam Physician, 1; 92 (1): 4350 .

[5] Heshmat Moayeri and Yahya Aghighi. (2004) A prospective study of etiology of short stature in 426 short children and adolescents in Archives of iranian medicine, 7 (1): 23-27.

[6] Strufaldi MW, Silva EM, Puccini RF. (2005). Follow-up of children and adolescents with short stature: The importance of the growth rate. Sao Paulo Med J.; 123: 128-33.

[7] Papadimitriou A, Douros K, Papadimitriou DT, Kleanthous K, Karapanou O, Fretzayas A. (2012). Characteristics of the short Children referred to an academic pediatric endocrine clinic in Greece. J Paediatr Child Health, 48: 263-7.

[8] Ahmid M Perry CG, Ahmed SF, Shaikh MG. (2016). Growth hormone deficiency during young adulthood and the benefits of growth hormone replacement. Endocr Connect, 5: R1-11.

[9] Mazouzi H, Elguendaoui S, Chadli A, Elghomari H, Farouqi A. (2006). Les étiologies du retard de croissance expérience du service d'endocrinologie et maladie métabolique du CHU Ibn Rochd de Casablanca. Annales d'Endocrinologie, 67: 440.
[10] Salhi H, Lahlou A, Dante ML, El OuahabiH , Boujraf S , Ajdi F. (2018). Stature-weight growth delays: Clinical and etiological aspects. Journal of Family Medicine and Primary Care Volume 7: Issue 5: 963-966.

[11] Yassine Iman. (2012). Doctor of Medicine thesis: growth hormone deficiency in children (about 32cases).

[12] Repositioning Nutrition as Central to Development. (2006). A Strategy for Large-Scale Action. Washington DC: The World Bank.

[13] M de Onis, C Garza, A W Onyango, M-F Rolland-Cachera. (2009). [WHO growth standards for infants and young children]. Arch Pediatr, 16 (1): 47-53.

[14] Barros FC, Victora CG, Scherpbier RW, Gwatkin D. (2010). Health and nutrition of children: equity and social determinants In: Blas E, Kurup AS, editors. Equity, Social Determinants and Public Health Programmes Geneva: World Health Organisation.49-75.

(http://Whqlibdoc.who.int/publications/2010/97824156397 0_eng.pdf.

[15] Synthesis of guiding principles on agriculture programming for nutrition. (2013). Final Draft. Rome: Food and Agriculture organization;

(http://www.fao.org/fileadmin/user_upload/wa_workshop/doc s/Synthesis_of_Ag-utr_Guidance_FAO_IssuePaper_Draft.pdf.

[16] UNICEF, Improving child nutrition: an imperative and achievable goal for global progress, New York, UNICEF, 2013. (http://www.unicef.org/french/publications/files/French_UNIC EF- NutritionReport_low_res_30May2013.pdf.

[17] Anastasios Papadimitriou, Konstantinos Douros, Dimitrios Papadimitriou, Kleanthis Kleanthous, Olga Karapanou, Andreas Fretzayas. Characteristics of the short children referred to an academic pediatric endocrine clinic in Greece. J Paediatr Child Health. 2012; 48 (3): 263-7.

[18] Nora soumya Fedala. Ali El Mahdi Haddam b, Akila Zenati c, Farida Chentli a. (2009). Le déficit en hormone de croissance chez l'enfant : formes cliniques et biologiques Revue francophone des laboratoires, 411: 63-70.

[19] Hanidoune. ML. (2014). Thèse de spécialité en Médecine : le retard statural chez l'enfant (à propos de 88 cas). Faculté de médecine et Pharmacie de Rabat.

[20] Liubiana Arantes de Araújo, Cássio Frederico Veloso, Matheus de Campos Souza, João Marcos Coelho de Azevedo, Giulio Tarro. (2020). The potential impact of the COVID-19 pandemic on child growth and development: a systematic review. J Pediatr (Rio J). 97 (4): 369-377. 